\title{
The Electronic Logging Device Mandate, Hours of Service Rules, and Implications for Southwest Florida Produce Haulers'
}

\author{
Fritz Roka, Tara Wade, and Craig Sprouse ${ }^{2}$
}

Electronic logging devices, or ELDs, became mandatory for commercial motor vehicles (CMV) on December 18, 2017 (FMSCA 2017a). On June 18, 2018, after two 90-day extensions, ELDs became mandatory for commercial produce haulers as well. The primary purpose behind requiring ELDs was to ensure greater compliance with existing hours of service (HOS) requirements by motor carriers and their drivers (Omnitracs 2018a). This article focuses on interstate movement of property (i.e., produce), and its objectives are to: 1) review HOS rules; 2) clarify agricultural exceptions to the HOS rules; and 3) offer a preliminary discussion as to how ELDs could affect south Florida produce growers.

\section{Hours of Service (HOS) Rules}

During the 1930s the US interstate trucking industry was expanding rapidly and a significant amount of freight began moving across the continental United States (Park 2018). The long-distance hauls raised safety concerns and experts made a causal link between driver fatigue and highway accidents. Hence, the first rules were established to limit hours of service for drivers of commercial motor vehicles (CMV). Yager (2009) outlined the evolution of HOS rules from the 1930s through 2008. In 1937, a driver could operate a CMV up to 10 hours during a 24-hour period and had to be "off-duty" for at least 8 consecutive hours before starting another 24-hour period. Total "on-duty" time was a maximum of 60 hours over 7 consecutive days. Changes in 1962 granted drivers more flexibility by shortening the "duty period" from 24 to 15 hours, extendable with breaks during the day. A driver still had to be "off-duty" for at least 8 consecutive hours per day and total "on-duty" time was limited to 60 hours over 7 days, or 70 hours over 8 days. Major changes to HOS occurred in 2003 when drivers could increase their driving time from 10 to 11 hours but only within a shorter 14 -hour driving window, a window not extendable with break times. Consecutive "off-duty" time increased from 8 to 10 hours. The weekly limits, 60 hours over 7 days, or 70 hours over 8 days, remained the same, but now drivers could "restart" their "on-duty" record by taking a break for 34 continuous hours. Other than requiring a 30-minute rest break after 8 hours of driving, the HOS rules have remained unchanged through September 2018 (FMCSA 2017b).

\section{Agricultural Exemptions}

Agriculture enjoys exemptions to the HOS rules so long as CMV drivers haul "agricultural commodities" or "farm supplies for agricultural purposes" within 150 air-miles (or 172.6 ground miles) of the "agricultural source" (FMCSA 2018). Agricultural commodity means any crop, non-processed food, feed, fiber, or livestock (including fish, bees, and insects). Farm supplies for

1. This document is FE1052, one of a series of the Food and Resource Economics Department, UF/IFAS Extension. Original publication date January 2019. Visit the EDIS website at https://edis.ifas.ufl.edu for the currently supported version of this publication.

2. Fritz Roka, associate professor of agricultural economics; Tara Wade, agricultural and natural resource economist; UF/IFAS-Southwest Research and Education Center; and Craig Sprouse, Sunripe Certified Brands; UF/IFAS Extension, Gainesville, FL 32611. 
agricultural purposes means products directly related to the growing or harvesting of agricultural commodities during the planting and harvesting seasons. Each state defines its own planting and harvesting seasons. The "source" of an agricultural commodity is the location at which an agricultural commodity is loaded onto an empty commercial motor vehicle (see https://www.fmcsa.dot. gov/regulations/hours-service/\%E2\%80\%9Cagriculturalcommodity\%E2\%80\%9D-exception-49-cfr-3951k1-hoursservice-regulations). The location may be any intermediate storage or handling location away from the farm or harvested field provided the commodity retains its original form and is not significantly changed by any processing or packing. If a driver makes multiple stops in the course of a single trip, the 150 air-mile exception applies only to the location of the original source and terminates when all agricultural products are off-loaded at the trip's final destination. This destination point can become a new source for a new trip and the 150 air-mile radius for an agricultural exception will be around that source. For a tomato growershipper, the agricultural source changes depending on what is being shipped and when the shipment occurs. Moving plants from a transplant house to the field makes the nursery an "agricultural source" during planting time. The "agricultural source" shifts to the field when a grower hauls harvested fruit to the packinghouse. When packed tomato cartons are shipped to a re-pack facility, another warehouse, or to a wholesale/retail distribution point, the packinghouse becomes an "agricultural source." With respect to the last scenario of moving commodities between packinghouses and other destinations within the supply chain, the HOS agricultural exemption requires that the commodity retains its original form and is not significantly altered by processing or packing. While a fresh market tomato is graded and ripened at a packinghouse, its condition is fundamentally the same as when it was picked in the field. Therefore, the 150-air-mile-radius exemption can be used at a tomato packinghouse. Juice oranges, on the other hand, are altered when they are crushed at the processing plant. The juiceprocessing plant would not be considered an "agricultural source," and transport of orange juice would not qualify for the HOS exemption.

The important implication of the agricultural exemption is that a CMV driver's on-duty and driving times while moving agricultural products within 150 air miles of its source are not counted toward his or her daily and weekly HOS limits. As an example, consider the shipment of round tomatoes from Immokalee, FL, to Hunts Point, NY. The driver starts his day at 7:00 am and spends the first hour fueling and conducting a safety inspection of his truck and trailer. At 8:00 am he begins loading his trailer. By noon, his trailer is fully loaded and he begins his trip to New York. At 3:00 pm he reaches the northern outskirts of Orlando, FL, which marks the 150 air-mile arc (172 ground-mile) from Immokalee. Because of the agricultural exemption, the HOS calculations for this particular trip starts at 3:00 pm. Feasibly, the driver could drive until 2:00 am the following morning before reaching the 11-hour HOS daily limit - though, technically, the driver is required to take a mandatory 30 -min rest break after 8 consecutive hours of driving. Whether driving a CMV for 14 consecutive hours as part of a 19 hour-day would be prudent and safe is doubtful. Nevertheless, such a day would be allowed under the agricultural exemption.

While the agricultural exemption permits drivers hauling agricultural products to waive HOS calculations within a 150 -air-mile radius, drivers and motor carriers still must maintain records of duty status (RODS) for seven consecutive days plus the current day (FMSCA 2018). Under the agricultural exemption, a driver could mark his paper logbook or annotate his ELD with "agricultural exemption" for the time he was driving and working within the 150-airmile radius.

\section{Electronic Logging Devices (ELDs)}

Motor carriers have been experimenting with automatic recording devices since the 1980s. Early devices were expensive. In 1995, a single device could cost as much as $\$ 2,500$ (Omnitracs 2018b). By 2016, advances in GPS technology and software pushed costs down to less than \$200 (Cruz 2017).The 2012 congressional act, Moving Ahead for Progress in the $21^{\text {st }}$ Century (MAP-21), required that all CMV hauling freight be equipped with ELDs. The final ELD rule was published in December 2015 and called for a four-year, three-part compliance phase-in. Phase 1, December 2015 through December 2017, was a transition period. During this period, ELD use was voluntary and operators had the option of continuing with paper logbooks or using previously installed logging devices. Phase 2, December 18, 2017, through December 16, 2019, requires all trucks to have installed ELDs unless they had previously installed an alternative electronic logging device before December 2017. Phase 3, which begins after December 16, 2019, requires all drivers and carriers to use self-certified ELDs that are registered with FMSCA (FMSCA 2017a). A certified ELD must:

1. connect directly to the truck's engine and provide a continuous record while the CMV is operating; 
2. allow a driver to select one of three options - "on-duty, driving," "on-duty, not driving," and "off-duty;"

3. quickly provide law enforcement with a graphical display of the driver's record of duty service; and

4. transfer data via a wireless system or with USB drives.

ELDs can accommodate the agricultural exemption for HOS rules. Within a 150-air-mile radius of an "agricultural source," a CMV driver can note within his ELD that he or she is operating under an "agricultural exemption." There are a few other exemptions to the ELD mandate which apply to interstate commerce:

1. All CMVs that are older than model year 2000 are exempt from using ELDs; and

2. drivers, agricultural or otherwise, who do not operate outside the HOS limits for more than 8 out of 30 days, are also exempt from having to purchase and maintain ELDs.

ELDs do not, in any way, change HOS rules. The primary purpose to mandate ELDs is to ensure compliance of motor carriers and their drivers with HOS rules as they currently exist (Omnitracs 2018a). Paper logs are not viewed as a reliable record of what drivers actually accrue as on-duty and consecutive driving hours. Proponents of ELDs argue that ELDs will increase the accuracy of HOS reporting, reduce paperwork for needed HOS compliance, and increase scheduling efficiencies for dispatchers by improving communications between drivers and dispatchers (Omnitracs 2018b). ELDs also have the capacity to record incidences of speeding, hard braking, and other engine functions. Accurate logging of CMV operations may also protect drivers from unrealistic or unsafe employer expectations that may encourage speeding or violating HOS rules.

\section{Implications of ELDs on South Florida Produce Haulers}

FMSCA estimated that reduced paperwork costs and higher fuel efficiencies resulting from mandatory adoption of ELDs would reduce freight costs across the United States by $\$ 1.6$ billion annually (Omnitracs 2018a). Many motor carriers argue that the cost of installing new ELD technology and stricter compliance with HOS rules will offset any savings (Cruz 2017). Trucking rates for produce have increased significantly. April 2018 data showed trucking rates were more than 20\% higher than in March 2017 (Karst 2018a). As recently as June 2018, rates increased between 16 and 35\% from the previous month (Karst 2018b). The extent to which ELDs by themselves are responsible for these rate increases is unclear. Strong economic growth within the United States, low unemployment, and a shortage of qualified CDL drivers are other important reasons for the recent rate increases. The cost of installing ELDs could force smaller, independent owner-operators out of the freight industry. If this is the case, then the shortage of CMVs and drivers will be exacerbated and likely push freight rates even higher.

ELDs could affect freight rates by tightening compliance with HOS rules and thereby increase the total time to move products from one point to another. To illustrate this point, consider an extreme case of compliance versus noncompliance with HOS rules when shipping two (2) trailer loads of tomatoes from Immokalee, FL, to Hunts Point, NY. Each refrigerated trailer holds 1,700 25-pound cartons $(\mathrm{CH}$ Robinson 2017). Now consider two drivers both earning the same annual income, $\$ 80,000$ per year, and working/ driving 250 days a year, or $\$ 320$ per day. The first driver operates within the HOS rules (compliant) and the second driver does not (noncompliant). HOS rules restrict the first driver to 11 hours of driving per day, and if he averages 60 miles per hour, he travels 660 miles per day. The second driver averages the same speed (i.e., 60 miles per hour), but drives 15 hours, four hours beyond HOS limits. The trip from FL to NY is 1,253 miles (http://www.distance-cities. com). The second driver travels 900 miles per day and completes his trip in 1.4 days ( 1,253 miles divided by 900 miles per day). Abiding by HOS rules, the first driver takes 1.9 days to complete the same trip (1,253 miles divided by 660 miles per day), or $36 \%$ more time than the second, noncompliant driver. Assuming both drivers continue to earn the same daily income (\$320), the difference in cost of the first driver (compliant, \$608) and the second driver (noncompliant, \$448) is \$160. Given 1,700 cartons per load, abiding by HOS rules increased costs from added driver time by $\$ .09$ per carton ( $\$ 160 / 1,700$ cartons).

While costs to ship tomatoes and other produce out of south Florida will likely increase with ELDs, a more important question is how ELDs will affect freight costs from other areas of the country. Mexican produce comes through McAllen, TX, and Nogales, AZ. Much of that produce is shipped to East Coast markets in direct competition with south Florida's growers. We examine how ELDs could benefit south Florida growers using the following parameters:

- Destination: Hunts Point, NY; 
- Trailer capacity: 1,700 25-pound cartons of round, mature-green tomatoes;

- Driver income: $\$ 80,000 /$ year; 250 driving days per year; or $\$ 320$ per day;

- Driving speed: 60 miles per hour;

- HOS with ELD: 11 hours per day; 660 miles per day;

- HOS without ELD: 15 hours per day; 900 miles per day.

Table 1 summarizes the number of days and average cost required to complete trips from each starting point to Hunts Point, NY, given the specified parameters. Freight costs for HOS-compliant drivers from McAllen, TX, and Nogales, AZ, would be 6 cents and 10 cents more per carton, respectively, than those from south Florida. While growers do not pay freight costs to move produce from their packinghouses to terminal sale points, stricter adherence to HOS rules provides south Florida growers with a competitive advantage from relatively lower freight costs.

\section{Concluding Comments}

ELDs are mandated across a large portion of the freight industry, including trucks hauling fresh produce. The primary purpose of ELDs is to ensure that motor carriers and their drivers follow HOS rules. The agricultural exemption provides agricultural producers and haulers a radius of 150 air-miles in which HOS and ELDs are not required. Ultimately, south Florida produce growers will be impacted by ELDs as most of their output is exported out of state to East Coast and northern US markets, well beyond the 150 -air-mile radius. There is still some debate over whether the net effect from ELDs will increase or decrease overall costs. In time, as motor carriers and drivers adapt to the new technology, we will see whether the cost reduction in paper work and/or fuel and logistic efficiencies will offset the cost of the ELD equipment and the "flexibility" drivers enjoyed when HOS were not being recorded by ELDs. For south Florida growers, specifically, greater compliance with HOS rules may provide a competitive advantage because their produce markets along the East Coast of the United States are geographically closer than Texas or Arizona, where most Mexican produce enters the United States.

\section{References}

Cruz, A. 2017. "ELD mandate will increase costs." American Trucker, July 31, 2017. http://www.trucker.com/print/3091. Accessed April 24, 2018.

FMCSA (Federal Motor Carrier Safety Administration). 2018. Agricultural Exceptions and Exemptions to the
FMCSA Hours of Service (HOS) and Commercial Driver's License (CDL) Rules. June 19, 2018. https://www.fmcsa. dot.gov/hours-service/elds/agricultural-exceptions-andexemptions-fmcsa-safety. Accessed June 22, 2018.

FMSCA. 2017a. Implementation Timeline. August 31, 2017. https://www.fmcsa.dot.gov/hours-service/elds/ implementation-timeline. Accessed June 2, 2018.

FMCSA. 2017b. Summary of Hours of Service Regulations. March 9, 2017. http://www.fmcsa.dot.gov/regulations/ hours-service/summary-hours-service-regulations. Accessed June 18, 2018.

Grower Alliance. 2011. Website accessed July 2, 2018. http://groweralliance.net/products/tomatoes/

Karst, T. 2018a. "Survey shows muted supply effect of ELD enforcement." The Packer. April 23, 2018. https://www. thepacker.com/article/survey-reveals-muted-supply-effecteld-enforcement. Accessed June 1, 2018.

Karst, T. 2018b. "Truck rules help produce haulers with hours of service, ELDs." The Packer. June 7, 2018. https:// www.thepacker.com/article/truck-rules-help-producehaulers-hours-service-elds. Accessed June 18, 2018.

Omnitracs. 2018a. ELD Facts. https://eldfacts.com/eldfacts/. Accessed April 18, 2018.

Omnitracs. 2018b. ELDs - Separating Facts from Fiction. https://eldfacts.com/eld-myths/. Accessed April 24, 2018.

Park, J. 2018. "Where did the Hours of Service Rules come from, anyway?” HDT Truckinginfo. March 15, 2018. https://www.truckinginfo.com/279731/where-did-thehours-of-service-rules-come-from-anyway. Accessed June $25,2018$.

Robinson, C. H. 2017. Contract Trailer Equipment. https:// www.chrobinson.com/en-us/-/media/chrobinson/newspdf/truckloadequipmentguide.pdf. Accessed July 2, 2018.

Yager, T. 2009. Commercial Motor Vehicle Drivers' Hours of Service: Background Information. Federal Motor Carrier Safety Administration, MCSAC presentation, December 7, 2009. https://www.slideserve.com/Jims/ commercial-motor-vehicle-drivers-hours-of-service. 
Table 1. Additional cost of shipping tomatoes to Hunts Point, NY, for HOS-compliant drivers.

\begin{tabular}{|c|c|c|c|c|c|c|}
\hline \multirow[t]{2}{*}{ Starting Point } & \multirow{2}{*}{$\begin{array}{c}\text { Mileage } \\
\text { Miles }\end{array}$} & \multicolumn{2}{|c|}{ Days to Complete Trip } & \multirow{2}{*}{$\begin{array}{c}\text { ELD Extra } \\
\text { Time } \\
\text { Days }\end{array}$} & \multirow{2}{*}{$\begin{array}{c}\text { Added Cost in } \\
\text { Driver Income } \\
\text { \$/Trip }\end{array}$} & \multirow{2}{*}{$\begin{array}{c}\text { Added Cost per } \\
\text { Carton } \\
\$ / C t n\end{array}$} \\
\hline & & ELD Noncompliant & ELD Compliant & & & \\
\hline Immokalee, FL & 1,253 & 1.4 & 1.9 & 0.5 & $\$ 160$ & $\$ 0.09$ \\
\hline McAllen, TX & 2,003 & 2.2 & 3.0 & 0.8 & $\$ 256$ & $\$ 0.15$ \\
\hline Nogales, AZ & 2,497 & 2.8 & 3.8 & 1.0 & $\$ 320$ & $\$ 0.19$ \\
\hline
\end{tabular}

